\title{
La production agricole connaît une forte croissance
}

Dernière mise à jour : 1 mars 2017

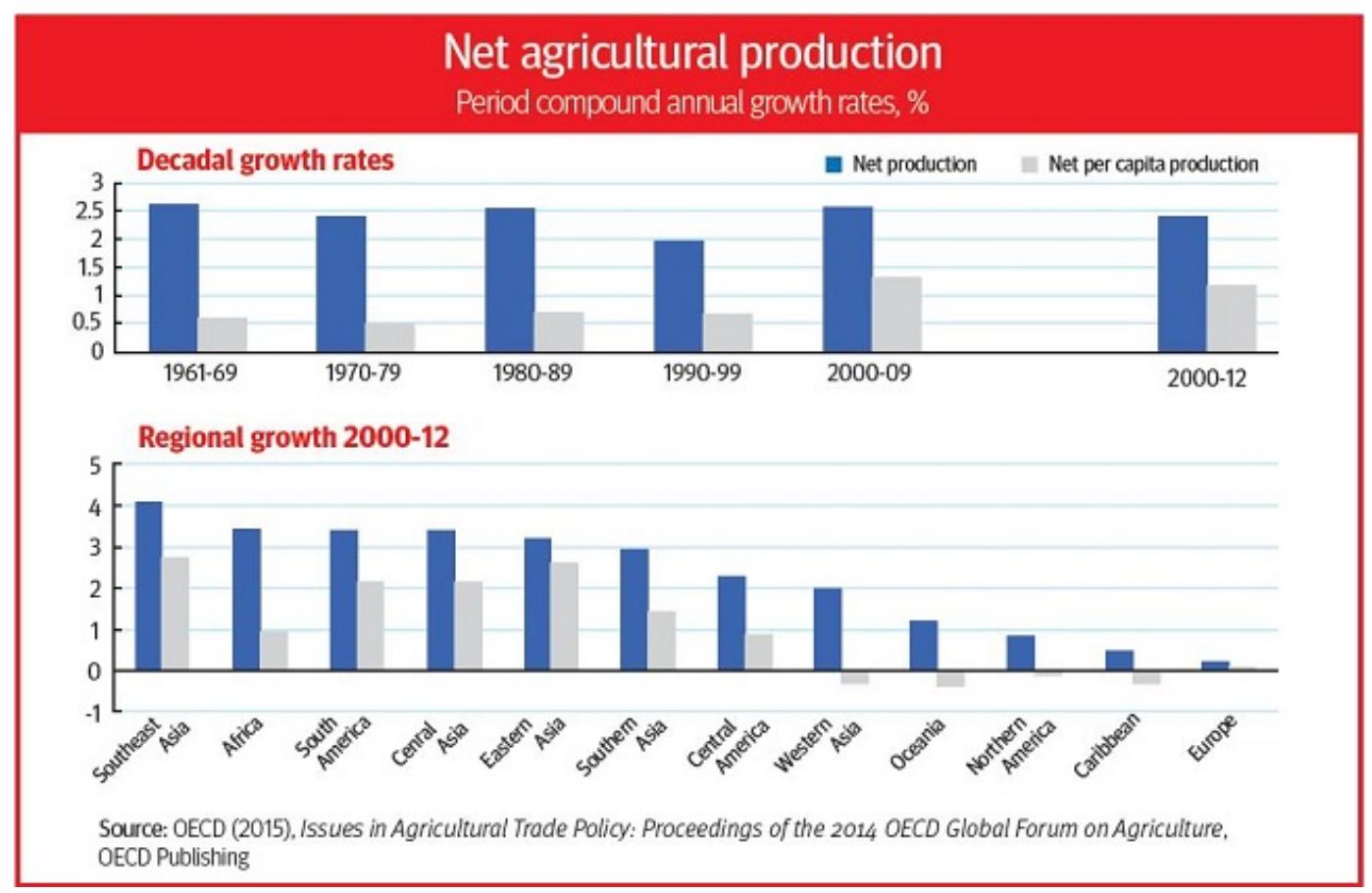

L'agriculture ayant déjà su répondre à l'évolution de la demande dans le passé, on pourrait prétendre que la sécurité alimentaire est plus une question d'accessibilité financière que de production.

En effet, la production agricole mondiale augmente nettement depuis plusieurs années. Dans les années 2000, son taux de croissance annuelle composé global a été supérieur à celui des années 1990, retrouvant son niveau des décennies antérieures, d'environ $2.5 \%$ par an. Elle a alors connu, aussi, une croissance par habitant inédite, presque deux fois plus rapide qu'auparavant. Ces chiffres témoignent d'une forte productivité, l'écart entre l'augmentation de la production et la croissance démographique étant toujours resté plus grand pendant cette période qu'au cours des 40 années précédentes.

La balance semble désormais pencher du côté des marchés émergents. Comme dans les années 1990, la croissance de la production mondiale a été forte dans les 
années 2000 en Amérique du Sud et en Asie du Sud Est, et elle n'a pas été négligeable dans d'autres régions d'Asie. Cependant, elle a été nettement plus faible en Europe et a même baissé, par habitant, en Amérique du Nord, ce qui indique que ces régions voient leur importance diminuer à cette aune.

Parallèlement, la croissance de la production totale s'est établie à plus de $3 \%$ par an en Afrique, mais, par habitant, elle a été beaucoup plus lente que dans les autres régions en développement.

Voir www.oecd.org/agriculture 